\title{
Segregação espacial e música eletrônica: a cena cultural soteropolitana ${ }^{1}$
}

\author{
Maria Auxliadora da Silva ${ }^{2} \&$ Juliana Cunha Costa $^{3}$ \\ ${ }^{2}$ Prof.- Dr. do Programa de Pós-Graduação em Geografia da Universidade Federal da Bahia, da disciplina O Espaço Geográfico na \\ Literatura e orientadora de mestrado e doutorado sobre Geografia, Literatura e Arte. e-mail: dorasilv@ufba.br \\ ${ }^{3}$ Mestre em Geografia pelo (POSGEO/UFBA) Programa de Pós-Graduação em Geografia, pela Universidade Federal da Bahia; \\ doutoranda no pelo Programa de Humanidades Interculturais na Escola de Humanidades e Ciências Sociais da Jacobs University \\ Bremen.e-mail:j.costa@jacobs-university.de
}

Recebido em 04/2012. Aceito para publicação em 12/2012.

Versão online publicada em 01/02/2013 (http://seer.ufrgs.br/paraonde)

\begin{abstract}
Resumo - A música eletroacústica destaca-se por ser um estilo musical essencialmente urbano que se inseriu no campo acadêmico em meio aos novos paradigmas da modernidade. Esses, que alteraram o modo de vida das pessoas das cidades, transformaram os elementos da paisagem e transgrediram as barreiras geográficas continentais, misturando-se aos outros elementos culturais que a transformaram em música eletrônica. Ao ser introduzida na esfera de consumo de massa, a música eletrônica perde seu caráter alternativa e se torna produto cultural - o que pode ser visto a partir da contextualização dos principais agentes de Salvador e de Camaçari, no estado da Bahia, ao segregarem o espaço destinado ao entretenimento. Assim sendo, nesta pesquisa, a música foi utilizada para delimitar os espaços de segregação construídos na capital baiana e em Camaçari a partir da observação das festas de música eletrônica em uma boate, na apropriação do seu espaço público para a realização da festa carnavalesca pelos trios elétricos e camarotes de música eletrônica e, finalmente pelas raves.
\end{abstract}

Palavras-Chave: Geografia Cultural. Geografia Urbana. Segregação.

\section{A música eletrônica sob a luz da geografia cul- tural}

[...] entender a experiência dos homens no meio ambiente e social, compreender a significação que esses impõem ao meio ambiente e o sentido dado às suas vidas. A abordagem cultural integra as representações mentais e as reações subjetivas no campo da pesquisa geográfica. (CLAVAL, 2002, p. 20).

A abordagem cultural, na ciência geográfica apresentou seu desenvolvimento a partir dos estudos das representações, pois, o acesso à realidade se dava através dessas "[...] representações e imagens [...]" (CLAVAL, 2008, p. 15). As teorias e os fundamentos geográficos passam a sustentar-se nos fenômenos de características culturais que influenciam a configuração do espaço (ibid). Desse modo, os geógrafos podem apresentar a espacialidade humana através de manifestações que se expressam por meio da literatura, das artes plásticas, da pintura, da dança, do ritual, da música e de muitas outras formas culturais.

As diversas produções musicais compõe um dos acervos culturais que auxiliam pesquisadores de diversos campos do conhecimento a avaliarem, por exemplo, o comportamento pelo qual os indivíduos se organizam e atuam na sociedade. É importante refletir que, em toda essa estrutura epistemológica, o espaço geográfico serviu de elemento-base na construção de uma obra artística, uma vez que, por meio de uma produção musical, todo um contexto sócio espacial pode ser revelado.

Muitas letras de canções possuem uma explicita referência espacial, constituindo-se em verdadeiras celebrações de lugares ou, ao contrário, em contestações referenciadas às condições de vida em determinados lugares. Do ponto de vista da melodia, há nítida correlação entre música e região. (CORRÊA; ROSENDAHL, 2007, p. 13).

${ }^{1}$ Este artigo é resultado da dissertação de mestrado desenvolvida no Programa de Pós-Graduação em Geografia, pela Universidade Federal da Bahia sob a orientação da Prof $\stackrel{a}{\text {. Dr }}$ - Maria Auxiliadora da Silva. Dissertação defendida no dia 09/09/2010 e publicada no ano de 2011. 
Na maioria das vezes, o som é produzido por meio de instrumentos musicais, sendo que cada sociedade os cria ou os adapta a partir dos seus recursos disponíveis. Ainda é possível pensar nos aparelhos eletroacústicos que - inicialmente construídos no decorrer do século XIX - têm o propósito de reproduzir sons semelhantes aos dos instrumentos clássicos ou aqueles semelhantes aos maquinários e robóticos, além de criar novos, totalmente singulares.

Os primeiros registros desses instrumentos eletroacústicos são datados do início do século passado, em 1906, por exemplo, com o Telarmôni$0^{4}$. Mas foi essencialmente com a invenção do sintetizador, no ano de 1917, que o russo Leon Theremin cria o Theremin ${ }^{5}$, o que mais tarde, nos anos 60 do mesmo século, proporcionou ao americano, Robert Moog, conceber o moderno Sintetizador Moog $^{6}$.

O sintetizador teve grande repercussão no mercado de instrumentos musicais; a cada ano, novos modelos e funções estavam disponíveis, favorecendo o crescimento do interesse nas técnicas para uso do mesmo. Este instrumento se tornou muito popular nos anos de 1970, promovendo o surgimento de bandas de música eletrônica. Dentro desse conjunto, o grupo Kraftwerk ${ }^{7}$, provindo de Düsseldorf, na Alemanha, é apreciado como principal representante de um movimento musical que se utilizou especialmente dos sintetizadores para construir sua base estética no denominado Techno Pop. 0 próprio progresso da tecnologia proporcionou aos $\mathrm{DJs} \mathrm{s}^{8}$, aqueles que produzem e performan a música eletrônica, recursos que o permitiu executar ao vivo, sons que antes eram criados e gravados apenas em estúdio.

A música eletrônica se apresentou como a trilha sonora de uma sociedade imersa em um período de grande metamorfose sociocultural e as fronteiras geográficas não foram suficiente para impedir a globalização desse estilo musical. De tal modo, este artigo explorá três instâncias pela qual a música eletrônica se projeta como principal forma para analisar a segregação urbana na capital baiana e em Camaçari, localizada na Região Metropolitana de Salvador, compreendida no período de 2005 a 2010.

\section{Contextualização dos espaços das festas}

A grande ocorrência de diferentes eventos musicais na Bahia é apenas uma parte do conjunto de estratégias de marketing desenvolvido pelo Estado. Esse se utilizou do título "Terra da Alegria", principalmente divulgado por autoridades das Secretarias do Turismo e da Cultura, com o objetivo de atrair investimentos de capitais privados para o Estado direcionados ao segmento de entretenimento e a fim de conquistar a preferência dos turistas de outras partes do Brasil e do mundo, com a intenção de aumentar a participação desse público nas principais festas da região, como o carnaval.

Contudo, integram-se neste artigo os espaços mais significativos dentro da esfera de espetáculos de música eletrônica na capital baiana e no município de Camaçari. A primeira será representada pela Boate Madrre localizada na Pituba, um dos bairros com o metro quadrado mais valorizado da capital baiana. 0 segundo, espacializando-se na Orla Marítima de Salvador, será representado através dos trios elétricos e camarotes que performan música eletrônica no carnaval; e por último, as raves ${ }^{9}$, produzidas pelo grupo Soononmoon e realizadas no Rancho Aurora, na cidade de Camaçari. A pesquisa que gerou este artigo foi realizada no período de 2008 até 2010; onde buscou des-

${ }^{4}$ Telharmonium ou telarmônio foi construído por Thaddeus Cahill em 1897 é "[...] um instrumento eletromecânico que, controlado por um teclado polifônico, produzia correntes elétricas de diferentes frequências de áudio. 0 som era amplificado por um sistema mecânico similar ao do fonógrafo. Este aparelho é registrado como o primeiro dispositivo eletrônico de geração de som" (CORRÊA, 2008, p. 81).

${ }^{5} \mathrm{O}$ aparelho possui duas antenas que geram um campo magnético; o intérprete controla o volume aproximando uma das mãos da antena esquerda, na vertical; já a altura é controlada aproximando-se a outra mão da antena direita" (ARANGO, 2005, p. 44).

${ }^{6}$ O sintetizad or foi essencial para a disseminação popular da música eletrônica, pois anteriormente ela estava restrita aos laboratórios dos centros de pesquisas em universidades e estações de rádios.

"“O nome da banda (Usina de Força) reúne os dois intuitos iniciais: a identidade alemã e a temática da indústria” (ARANG0, 2005, p. 139).

"'DJ é o diskjockey, o manobrador dos discos, o programador musical [...] Ele é identificado pelo público, nos eventos, por seu estilo e seleção musical" (SOUZA, 2001, p. 52).

"'Termo derivado do inglês que significa falar com extremo entusiasmo ou delírio. Trata-se de um evento que acontece em lugares afastados do centro urbano, com longa duração, que pode ultrapassar doze horas. Tem a presença de DJs e de artistas plásticos, visuais e performáticos que apresentam seus trabalhos, interagindo com o público" (COSTA; NUNES, 2008, p. 115). 
mistificar a ideia atrelada à música eletrônica com o aspecto alternativo, visão defendida pelos produtores das primeiras raves realizadas na cidade de Salvador na década de 1990. Elas foram perdendo suas características de festas alternativas quando se profissionalizaram ao ponto de contar com uma grande infraestrutura e hiper-inflação dos produtos ali comercializados. As boates já foram concebidas dentro dos ambientes de casas noturnas e, por isso, sua compreensão é semelhante à do carnaval, pois é necessário pagar para adentrar em ambos os espaços. Sendo assim, é possível perceber como essas três formas de eventos de música eletrônica se apresentam com muito profissionalismo. Recebem apoio e/ou patrocínio de empresas privadas, as quais têm suas marcas e produtos comercializados com exclusividade, já que compram o espaço da festa para terem suas marcas anunciadas em um ambiente hiper-valorizado, pensando na lógica do marketing.

No capitalismo é a ideologia da burguesia que alcança status hegemônico e, assim, é sua cultura que define o senso comum [...] No capitalismo, produção significa a produção de mercadorias para um mercado, e outras atividades sociais humanas são excluídas da esfera produtiva para serem reificadas nas várias partes da "superestrutura". (COSGROVE, 2003, p 120).

No capitalismo é a ideologia da burguesia que alcança status hegemônico e, assim, é sua cultura que define o senso comum [...] No capitalismo, produção significa a produção de mercadorias para um mercado, e outras atividades sociais humanas são excluídas da esfera produtiva para serem reificadas nas várias partes da "superestrutura". (COSGROVE, 2003, p 120).

\section{A música eletrônica como forma de segreção urbana}

A cidade produzida liga-se à forma de propriedade que reproduz a hierarquia espacial enquanto consequência da hierarquia social passível de ser percebida na paisagem urbana através da segregação espacial cuja dinâmica conduz, de um lado, à redistribuição do uso das áreas já ocupadas, levando a um deslocamento de atividades e dos habitantes e, de outro, a incorporação de novas áreas que criam novas formas de valorização do espaço urbano. (CARLOS, 2007, p. 37).

Muitos empresários do ramo do entretenimento encontram, tanto na Orla de Salvador, como também em outros bairros nobres da capital, o melhor espaço para implantação de clubes ou boates de música eletrônica com padrão de alto nível. Esse fenômeno se faz presente ultimamente porque existe uma maior aceitação do público soteropolitano para estes eventos comparado aos últimos dez anos. Todavia, isto vem a dificultar, por exemplo, a presença de indivíduos do Miolo ou do Subúrbio de Salvador, pela razão que eles dependem, na grande maioria, dos transportes públicos, que têm sua frota reduzida durante a noite.

Esse crescimento vem atraindo a atenção dos indivíduos pertencentes às classes mais elevadas; assim sendo, são aqueles de maior poder aquisitivo que participam ativamente dessas festas. "Finalmente, Salvador entrou para a rota de consumo dos playboys e endinheirados. É impressionante como se consome, e o que se gasta, nas principais cidades do mundo dentro de casas noturnas" (DAIHA, 2009, s.p). Esta homogeneidade do público iluminou as questões a serem debatidas sobre a segregação ocorrida nas boates de Salvador nos eventos de música eletrônica.

O fenômeno da segregação se apresenta de muitas maneiras e aqui é possível delineá-lo através da variável econômica - a mais significativa dentro do contexto da manifestação da música eletrônica - principalmente quando são vislumbradas as práticas desse tipo de espetáculo em um espaço que privilegia a ausência dos indivíduos de classes sociais inferiores em decorrência, por exemplo, dos altos valores impostos aos ingressos e aos produtos ali comercializados. Uma vez que, o consumo com os produtos e serviços mais lucrativos para a boate estão diretamente ligados ao público que possui mais dinheiro, pois é ele que paga pelos ingressos mais onerosos, além de consumir os produtos mais caros. Esse é um dos motivos pelo qual eles são alocados em ambientes privilegiados " $f a$ zendo-o" consumir mais os melhores produtos do que aqueles que permanecem em espaços sem muito conforto dentro do ambiente interno da boate.

A estrutura da boate segue a norma de valorização do espaço, pois os ingressos são cotados a diferentes valores em decorrência da localização que o indivíduo vai ocupar. Na parte inferior da Boate Madrre ${ }^{10}$ existem duas áreas: dois camarotes nas laterais e uma "pista" ao centro. É nessa última

\footnotetext{
${ }^{10}$ As subsequentes narrações e explanações acerca da boate Madrre foram realizadas durante a prática de campo,
} 
que estão concentrados os indivíduos que pagam os ingressos mais baratos, em que o público tem a visão do palco de baixo para cima, e apenas um sofá, no meio da pista, oferece conforto para os que dançam durante a noite. Na parte superior, nas laterais, existem dois camarotes, os quais são os espaços mais valorizados da Madrre: ambiente confortável, com mesas e poltronas, bares e atendimento personalizado, tudo de mais requintado para receber o público que mais dispõe de dinheiro.

As mulheres e os homens que transitam pelos dois espaços internos da boate fazem parte do grupo de jovens da classe média soteropolitana, habitantes dos bairros adjacentes à Orla Marítima, e possuidores de bons níveis de instruções. Destaca-se a rara presença de negros ou pardos nesse grupo, mesmo eles sendo a maior parte da população de Salvador. Segundo o censo de 2000, cerca de 2.027.779 pessoas soteropolitanas são negras, perfazendo $83 \%$ da população (PLANO MUNICIPAL DE SAÚDE, 2009). Entretanto, grande parte dessa corresponde aos mais marginalizados perante o acesso aos serviços públicos, a distribuição de renda e de riquezas, ou seja, a parcela mais pobre da população de Salvador.

A estrutura da boate funciona como uma fronteira que separa os "pobres" dos "ricos", oferecendo aos mais abastados financeiramente, o espaço ideal para o gozo de momentos dançantes ao som da música eletrônica, em um território totalmente privado. 0 contrário acontece no carnaval, pois os organizadores de blocos de trios e de camarotes utilizam a mesma estrutura, já montada pela Prefeitura de Salvador, para seus fins econômicos, quando privatizam os espaços públicos para proporcionar ao mesmo público-alvo outros momentos de prazer. 0 geográfo baiano Dias (2002) ilustra de forma sucinta a sua visão sobre a festa de maior representatividade para a economia soteropolitana: o carnaval.

[...] é possível afirmar que a festa, mesmo expressando as mais legítimas representações dos habitantes da cidade, sempre foi um palco de intensos conflitos que resultavam em exclusões e segregações, principalmente da popu- lação pobre e negra. (DIAS, 2002, p. 2).

O carnaval soteropolitano se encontra reservado aos grandes conglomerados liderados por artistas baianos. Dois dos mais expressivos exemplos são o Camaleão Comércio e Produções Artísticas Ltda ${ }^{11}$, que se torna uma das mais fortes e importantes corporações no ramo do entretenimento em Salvador, juntamente com o grupo Caco de Telha ${ }^{12}$, que agrega, em sua conta, 12 Unidades Estratégicas de Negócios, liderado pela baiana Ivete Sangalo. Essas são algumas das empresas responsáveis por monopolizarem os espaços das festas e por receberem as maiores taxas de patrocínios de companhias nacionais e multinacionais.

Um dos motivos fundamentais que levaram à privatização da festa é tratado por Dias (2001) como uma forma encontrada pela prefeitura para resolver os problemas da falta de recursos ao administrar grande parte da montagem do carnaval. Porém, algumas empresas, que conduzem os trios elétricos, vêm apresentando fraudes fiscais, sonegação de impostos e inadimplência, restando para a prefeitura a necessidade de "[...] assegurar maior justiça tributária, reduzindo a taxação sobre o micro comércio de rua e distribuindo melhor o peso da sustentação da festa entre Poder Público e grandes beneficiários privados" (INFOCULTURA, 2007, p. 24).

As empresas de entretenimento, detentoras dos blocos e dos camarotes ${ }^{13}$ privados, são as principais responsáveis pela segregação espacial que se determinou no carnaval de Salvador. Esse espaço criado para o gozo coletivo é também destinado ao conflito. Nesse caso, na dualidade das forças que estão constantemente em colisão: "[...] 'negro x branco', 'pobre x rico', [...], 'público x privado"' (MIGUEZ, 1996, p. 10). Esse fato é concretizado em decorrência da segmentação de público, proporcionada pelos agentes econômicos que visam, especialmente, a real possibilidade de arrecadação de grandes montantes de capital.

[...] ser pobre não é apenas ganhar menos do que uma soma arbitrariamente fixada; ser pobre é participar de uma situação estrutural, com uma posição relativa inferior dentro da

tendo sido inicializada às $22 \mathrm{~h} 27$ e finalizada às $04 \mathrm{~h} 38$ do dia 18/10/2008. Após a realização de uma saída de campo o fenômeno foi estudado através de depoimentos dos indivíduos que frequentam a boate Madrre no site de relacionamentos Orkut.

${ }^{11}$ http://www.camaleao.com.br

${ }^{12}$ http://www.cacodetelha.com.br

${ }^{13}$ Importante lembrar que alguns hotéis e pousadas constroem os seus camarotes utilizando seu próprio espaço privado, ou seja, eles não se apropriam do espaço público para a montagem da sua estrutura. 
sociedade como um todo. E essa condição se amplia para um número cada vez maior de pessoas. [...] a causa essencial da perversidade sistêmica é a instituição, por lei geral da vida social, da competitividade como regra absoluta. (SANTOS, 2000, pp. 59-60).

A ideia do camarote, que é transmitida pela mídia, promove a euforia dos indivíduos que almejam estar nesse espaço - ideal para assistir o desfile de carnaval - com conforto, exclusividade, requinte e acesso aos melhores alimentos e bebidas. Porém, os altos valores impostos pelos seus organizadores afastam, consideravelmente, a presença dos sujeitos da base da pirâmide social.

Essa afirmação fica muito evidente quando se analisa os dois tipos de públicos que participam da festa. A maior parcela dos frequentadores é dominantemente constituída por negros e pardos de baixa instrução - que, de alguma forma, não podem pagar os valores impostos pelos empresários. Eles “[...] denominados "pipocas ${ }^{14 "}$ continuaram sendo predominantes nas ruas da capital em 2008 (60\% do total)" (INFOCULTURA, 2009, p. 5), e procuram "[...] disputar o cada vez mais exíguo metro quadrado da rua com os cordões de seguranças, os ambulantes e as barracas dos comerciais da folia" (SERPA, 2007, p. 112).

O pipoca preenche os espaços vazios, historicamente ele pulava atrás do trio, e é difícil situá-lo em um segmento social específico, embora majoritariamente seja oriundo das classes populares. Ele foi o principal protagonista do carnaval de 1950 a 1990. (DIAS, 2002, p.115).

Esse público está cada vez mais sujeito aos inúmeros atos violentos contra sua pessoa, partindo dos policiais - que na grande parte agridem mais o folião pipoca do que um folião que se encontra dentro dos espaços empresariais -, dos cordei$\operatorname{ros}^{15}$, que visam impedir a tentativa de ultrapassagem da linha demarcada pela "corda", dos próprios seguranças dos blocos, que têm o dever de proteger a integridade física dos "associados", além dos atritos cometidos por eles mesmos quando dançam em um espaço muito pequeno que não comporta tão grande número de pessoas.

Para alguns estudiosos, nos últimos anos, a presença do sentido hierárquico tem prevalecido sobre a noção de igualdade, determinada pela profissionalização do Carnaval baiano ou, em outros termos, pela gestão mercantil da festa, que se expressa cada vez mais na divisão territorial das ruas, seja inicialmente pelas cordas que demarcam o espaço dos integrantes dos blocos, seja, mais recentemente, pelos camarotes, que têm sido apontados como os grandes vilões no debate sobre a "privatização do espaço público". (INFOCULTURA, 2009, p. 22).

Já o grupo dos mais afortunados, que pagam para transitar nos espaços privilegiados do carnaval, soma a exímia parcela do público total, e se divide entre foliões dos blocos (28\%) e dos camarotes (12\%) (INFOCULTURA, 2009, p. 5). Mais uma vez, a segregação carnavalesca também é social, pois os que participam dentro dos "[...] blocos de trio e camarotes, sobretudo os mais concorridos, são na maioria brancos com escolaridade elevada" (ibid, 2009, p. 5). Algumas vezes, é possível encontrar tanto indivíduos de baixo poder aquisitivo, que compraram na forma de crédito a entrada para a festa, quanto aqueles de alto poder aquisitivo que "[...] muitas vezes participam de camarotes patrocinados pelas grandes empresas e não efetuam gastos pessoais na festa" (ibid, 2009, p. 5). Eles possuem a tranquilidade para festejar o carnaval sabendo que estão protegidos pelos cordeiros e pelos seguranças particulares que impedem a todo custo a aproximação, principalmente, dos pipocas.

A música eletrônica foi inserida "oficialmente" no carnaval de Salvador no circuito Dodô (Barra/Ondina) ${ }^{16}$ por meio do trio elétrico da cantora baiana Daniela Mercury, quando, quando, no ano de 2000, essa convidou o DJ paulistano Mau $M a u$, considerado, naquela época, o melhor na sua categoria pela mídia e pelo público brasileiro. A

\footnotetext{
${ }^{14}$ Os foliões pipocas são pessoas que participam do carnaval do lado de fora das cordas dos blocos. Eles podem acompanhar os blocos e suas atrações musicais sem pagar, porém não têm os privilégios nem a segurança dos associados dos blocos (www.carnasite.com.br).

${ }^{15}$ Os cordeiros são uma espécie de seguranças, eles ficam alocados ao redor dos trios elétricos separando os foliões que fazem parte dos blocos pago dos foliões pipocas, utilizando uma corda para tal ação.

${ }^{16}$ Nos fins dos anos de 1980, o antigo circuito do Campo Grande inicia o seu processo de decadência, juntamente com a falência dos blocos carnavalescos tradicionais. Um novo espaço é implantado no circuito que abrange os bairros da Orla Marítima, compreendidos da Barra até a Ondina, hoje conhecido por Circuito Dodô, com 4 km de extensão. Esse acontecimento atrai, no início de sua fundação, os blocos alternativos e, paulatinamente, a atenção dos turistas e dos
} 
cantora percebeu que era possível utilizar pick$u_{p s}{ }^{17}$ em cima dos trios elétricos, uma vez que buscou inspiração nos festivais europeus. 0 resultado dessa primeira experiência baiana foi desastroso: a multidão escarnecia perante a tentativa de transformar o circuito do carnaval em uma boate andante. Mas esse fato não foi um empecilho, já que a cantora inaugurou o Trio Tecno, persistindo nesse estilo durante os anos de 2000 até 2005.

A primeira cantora a trazer música eletrônica para o circuito carnavalesco foi Daniela Mercury, há mais de dez anos. Na época, ela foi muito vaiada pelos foliões, que estranharam a mudança. Nos últimos anos, porém, o ritmo passou a fazer parte do Carnaval baiano. (FRANCISCO, 2010, s.p).

De um modo "alternativo" Daniela Mercury conduziu o carnaval de Salvador com o trio elétrico de música eletrônica durante cinco anos. Os DJs tinham a função primordial de entreter o público nos momentos em que não havia nenhum trio elétrico sendo apresentado durante os desfiles. Mas a própria lógica carnavalesca baiana institucionaliza, em sua programação, um estilo musical totalmente distante dos padrões até então conhecido pelo público do axémusic.

O caráter "alternativo" é incluído no circuito oficial da festa e a música eletrônica, rapidamente, se insere numa lógica "comercial" e torna-se um negócio estratégico que aproxima ainda mais os turistas estrangeiros para a prática de consumir o bloco de trio elétrico. Esse turista se identifica com os DJs internacionais já conhecidos do seu cotidiano, pois durante todos esses anos eles são considerados pelos organizadores o público de maior representatividade. A música eletrônica torna-se, desse modo, mais um nicho a ser explorado, tanto pelos donos de boate quanto pelos produtores dos trios elétricos de música eletrônica.

0 ano de 2006 foi então conhecido pela profissionalização da inclusão da música eletrônica na programação do carnaval baiano, tendo sido escolhido o circuito Barra-Ondina para sediar os desfiles dos trios elétricos desse estilo musical. Esse percurso possui o atrativo natural, a borda Atlântica de Salvador, que é o espaço ideal para o capital privado incentivar as atividades de serviços enfatizando o lazer, a cultura e o turismo. Aí é oferecido aos organizadores dos blocos de trio, maiores espaços destinados ao folião pagante, o que prejudica o folião-pipoca, já que a cada ano, vem se apresentado um congestionamento de trios elétricos o que impossibilita a sua circulação. Em todos esses anos, esse foi o único circuito destinado às apresentações dos trios elétricos de música eletrônica e aos camarotes mais requisitados pelo público de alta renda, pois eles oferecem em sua estrutura a grande presença dos DJs internacionais.

Foi nítido perceber, nos carnavais de 2007, 2008 e 2010, que a cada ano os blocos de música eletrônica apresentavam um crescimento vertiginoso no número de público pagante. Esse tipo de trio atrai, especialmente, a atenção dos jovens de classe média e alta, além dos turistas estrangeiros e nacionais. "A animação era grande dentro do bloco Skol, um dos maiores que passaram nesta terça pela Barra, especialmente dos turistas, que compõem a maioria dos integrantes" (CUNHA, 2009, s.p).

Diante desse cenário hedonista, os camarotes e os trios elétricos de música eletrônica compartilham a mesma lógica, seguida pelos demais, privatizando os espaços públicos e vetando a participação popular dentro da maior festa de rua do mundo. Mas esse processo é o contrário do que prega a música eletrônica, desde sua gênese e pelo modo como foi inserida no carnaval baiano; sua ideologia, trazida pelos seus precursores, é de uma música não comercial e que se sustenta sob bases do coletivismo. Todavia, esse fato não é consumado, pois os altos valores cobrados pelos organizadores não comumga com a realidade daqueles que sobrevivem à base de um salario mínimo. Esses dois opostos dialogam entre si em uma relação extrema de segregação sócio-econômica existente nos dois lados: dentro e fora da corda e dos camarotes.

jovens de classe média, “[...] reconfigurando sobremaneira a espacialidade do carnaval” (DIAS, 2001, p. 131). Em decorrência disso, os mais caros e concorridos camarotes localizam-se nesse espaço, descoberto como um território privilegiado.

${ }^{17}$ Pick up é o par de toca-discos utilizado pelos DJs em apresentações ao vivo. 
A primeira festa oficial, contemplada pela música eletrônica em Salvador, foi produzida pelo grupo Soononmoon no ano de 1997. 0 próprio DJ Nazca, primórdio remanescente desde a antiga formação desse grupo, afirma que hoje em dia esses eventos, não somente na Bahia, atraem muitos jovens, movimentam um mercado de música, turismo, produção de eventos que têm na rede mundial de computadores o seu principal ponto de encontro.

Após a primeira rave em Salvador, as demais produzidas pelo grupo Soononmoon foram realizadas em locais apropriados para sua materialização. "A produção de festas em lugares ermos, com seus muitos mistérios, implicava na ampliação da sensibilidade por música alta, luzes intensas e decorações psicodélicas" (GUSHIKEN, 2004, p. 41). Nessas festas, a busca da transcendência propicia diferentes tempos-espaços. $\mathrm{O}$ ato da dança não é coletivizado, é individual como a própria ótica da modernidade. Chêne (2006) descreve esse ato como uma "Dança do Afastamento", aludindo o modo como os indivíduos se comportam na atual sociedade, na qual é transmitida através do comportamento representado na maneira de dançar aleatoriamente.

É preciso investigar essa elaboração e o próprio ato de dançar porque eles são os sintomas de um ato corporal específico do mundo urbano relacionado simultaneamente à estética e ao social. A maneira pela qual, por exemplo, as pessoas se comportam no espaço público está ligada a essa maneira de dançar, porque é a mesma forma corporal que se manifesta. (CHÊNE, 2006, p.142).

A festa se espacializa em Camaçari, na Região Metropolitana de Salvador, no Rancho Paraíso, localizado no Vale da Aurora, a $3 \mathrm{~km}$ antes do pedágio da Linha Verde. Para sair e chegar nessa festa, é necessário recorrer aos automóveis próprios, ou a transportes coletivos, a vans ou ônibus que são conhecidos por bate-e-volta; essa alternativa é majoritária nas raves. Essa última opção é disponibilizada pelos próprios participantes através de uma rede de serviços que se estabelece no site de relacionamento Orkut. Os transportes custam em média $\mathrm{R} \$ 15,00$ apenas para o serviço de locomoção. Entretanto, empresas de turismo oferecem alguns outros serviços, além do transporte (serviço de bordo, coordenador de grupo, ingresso do evento e cobertura fotográfica), e o valor destinado é de $\mathrm{R} \$ 55,00$. Essas empresas não são utilizadas ape- nas pelos soteropolitanos, mas sim por pessoas de outros estados, como Sergipe. Esses ônibus possuem ar condicionado, música temática e bebidas incluídas, e o preço para tal serviço oscila em torno de $R \$ 60,00$.

De acordo com o sócio majoritário da Soonomoon, cada rave produzida por seu grupo consegue faturar entre $\mathrm{R} \$ 40$ mil a $\mathrm{R} \$ 70$ mil, ao contrário da boate Madrre, que em apenas uma noite pode faturar até R\$ 100 mil (no ano de 2010). Enquanto essa última já tem a estrutura física montada, a primeira necessita arcar com todos os equipamentos de som, aluguel de ambulância e paramédicos, estruturas metálicas, banheiros químicos, abastecimento com alimentos e bebidas, além do aluguel do espaço.

Assim como qualquer festa privada, a rave também possui os artifícios de separar os que pagam daqueles que não pagam pelos ingressos. Porém, não é comum a presença de pessoas que chegam até o local e não possuem ingressos. A entrada desse local é vigiada por seguranças e cães farejadores, homens e mulheres para realizarem revistas, diferentes pulseiras de identificação para convidados e público geral. Esse processo é alegado pelo DJ Nazca como necessário, pois evitará que alguém sujeito entre com uma quantidade excessiva de drogas ou alguma arma que venha ferir a integridade física dos participantes, além de alimentos e bebidas. Assim, “[...] os processos da repartição disciplinar tinham seu lugar entre as técnicas contemporâneas de classificação e de enquadramento" (FOUCAULT, 1999, p. 181) para manter uma ordem milimetricamente arquitetada pelos mecanismos de domínio dos organizadores da festa.

Não foi percebida nenhuma prática segregacionista no ambiente interno, pois todos territorializam-se de maneiras distintas, comungando do mesmo espaço geográfico. Não há nenhum espaço privado, ou até mesmo direcionado para determinada classe social pois, os ingressos possuem o mesmo valor tanto para homens quanto para mulheres. A única reclamação feita por todos os participantes é em relação ao preço dos produtos comercializados, já que são inflacionados. 0 produto mais procurado é a água mineral, em decorrência da desidratação por uso de drogas como esctasy; uma garrafa de $500 \mathrm{ml}$ de água custa, aproximadamente, $R \$ 4,00$; isso é motivo para que as pessoas burlem a segurança e tragam consigo seus alimentos e bebidas escondidos dentro das mochilas ou barracas de acampamento.

Nas raves, os processos compreendidos são de múltiplas identidades, cada indivíduo munido da sua individualidade faz do espaço um território 
com valor simbólico. Uma delimitação de espaços, mesmo que momentânea, se apresenta como um retrato dos elementos que vêm contribuindo para a construção de um individualismo moderno (CARLOS, 2007).

\section{Considerações Finais}

A música eletrônica foi, paulatinamente, favorecida no início da década de 1980, em decorrência do rápido avanço das técnicas e da fluidez das informações pela malha geográfica. Em diversos países, os novos músicos e grupos atentaram para os aparelhos eletrônicos para produzirem música, juntamente com a sua respectiva singularidade cultural, que vai produzir muitas sonoridades e estilos musicais. Até então, ela foi associada às práticas não comerciais e alternativas. Porém, quando é absorvida para a esfera da cultura de massa, a indústria fonográfica vai segmentando o seu público e transforma a música em mais um produto rentável para os grandes detentores do capital que a hiper-valoriza.

A segregação espacial é materializada pela falta de infraestrutura pública para a democratização do lazer daqueles que habitam as áreas populares, porque democratizá-los seria também abrir mão dessa segregação espacial. Já o lazer privado é reservado, em grande parte, para aqueles habitantes das áreas nobres, pois os valores financeiros destinados ao seu uso não comungam com a realidade vivida pelos pobres que têm os piores níveis salariais ou encontram-se desempregados.

A primeira forma de entretenimento analisada foi a boate: uma estrutura de lazer noturno direcionada, principalmente, para a execução de música eletrônica. Nela, a observação do ambiente foi importante, pois observar e apreender o momento pôde transcrever, sensivelmente, os aspectos segregacionistas. Dentre eles principalmente está o preço dos ingressos e o valor cobrado pelos produtos e serviços internos.

O carnaval se apresenta com nitidez como o uso do espaço público para geração de renda de alguns grupos privados que segregam os foliões "pipocas", enquanto o grupo de influência econômica age sobre o território público com a finalidade de apropriação para a geração de lucro através dos camarotes e blocos de carnaval patrocinados muitas vezes por empresas multinacionais. No "carnaval eletrônico" a realidade não é diferente, porque os ingressos cobrados para participar como "associado" não permitem que os foliões de classes econômicas mais baixas paguem por eles. As ruas da Barra e da Ondina, localizadas na Orla Marítima de
Salvador, que antes eram trafegadas por eles, agora dão passagem, tranquilamente, para os trios, os DJs e os foliões, na sua grande maioria estrangeiros e jovens brasileiros de classe média.

Nas raves, o processo não é diferente. 0 ingresso em si não é um grande empecilho financeiro, porém o acesso até o local e a alimentação demanda maiores despesas, pois os valores inflacionam à medida que a procura pelo produ to é maior. Dentro do espaço interno da rave não foi percebida a prática da segregação, porque todos os participantes podem assumir múltiplas territorialidades. Porém, aqueles que não podem sustentar, financeiramente, um dia de festa não participam, ainda mais o Rancho Aurora estando tão distante dos demais equipamentos urbanos e das edificações da capital baiana. Mas a própria constituição desse tipo de música veio excluindo paulatinamente a tentativa de aproximação dos indivíduos pobres, que possuem somente o acesso aos ritmos mais difundidos de forma agressiva pelo mercado fonográfico baiano, como o Axé Music.

Enfim, pode-se afirmar que a música é também uma forma de pesquisar a espacialização humana e avaliar as suas consequências em um contexto maior, que inclui o espaço e as representações culturais. Essa artigo, decorreu de uma pesquisa que se apoiou nas teorias científicas para compreender as práticas do cotidiano, a fim de trazer um resultado que transcrevesse uma realidade mascarada pelo discurso de uma música alternativa. 0 diálogo entre a música eletrônica, espaço urbano, entretenimento e segregação trouxe à discussão condições básicas para futuras análises que possam preencher lacunas vindouras de um estilo musical que se popularizou em uma festa massiva, de grande repercussão, e selecionando os que dela participam.

\section{Referências}

ARANGO. Julián Jaramillo. Homens, máquinas e homens-máquinas: o surgimento da música eletrônica. Dissertação de Mestrado em Multimeios - UNICAMP - Universidade Estadual de Campinas, 2005.

CARLOS Ana Fani Alessandri. 0 lugar no/do mundo. São Paulo: Edição Eletrônica/ LABUR, 2007.

CHÊNE, Aurélie. Percepções corporais do mundo urbano. In: JACQUES, Paola B. JEUDY, Henri P. Corpo e cenários urbanos: territórios urbanos e políticas culturais. Salvador: EDUFBA, p. 141152,2006. 
CLAVAL, Paul. A volta do cultural na geografia. Revista Mercator, Fortaleza, ano 01, n. 01, p.1928, 2002.

CLAVAL, Paul. Uma, ou Algumas, Abordagem(ns) Cultural(is) na Geografia Humana?. In SERPA, Angelo (Org). Espaços culturais: vivências, imaginações e representações. Salvador: EDUFBA, p. 13$32,2008$.

CORRÊA, Roberto Lobato; ROSENDAHL, Zeny. Literatura. Música e Espaço: Uma Introdução. In: CORRÊA, Roberto Lobato; ROSENDAHL, Zeny (Orgs). Literatura, música e espaço. Rio de Janeiro: UERJ, p. 7-16. 2007.

CORRÊA. Elenice Mattos. Parangolés eletrônicos: expressões audiovisuais de uma estética do silício. Dissertação (Mestrado) - Universidade do Vale do Rio dos Sinos. Programa de Pós-Graduação em Ciências. 2008.

COSGROVE, Denis. Em direção a uma geografia cultura radical: problemas da teoria. In: CORRÊA, Roberto L.; ROSENDHAL, Zeny (Orgs). Introdução à geografia cultural. Rio de Janeiro: Bertrnd Brasil, p.103-146, 2003.

COSTA. Juliana Cunha; NUNES. Camila Xavier. Carnaval, Raves e Shows Populares em Salvador: a lógica globalizante da cidade espetáculo. In: CONCEIÇÃO, Fernando (Org.). Educação, Comunicação e Globalitarismo. A partir do pensamento de Milton Santos. 1 ed. v. 1, Salvador: EDUFBA, p.113-121, 2008.

CUNHA. Lucas. 0 amor de Fatboy Slim e a paixão de David Guetta pelo Carnaval. A Tarde On Line. 2008. Disponível em: <http://www.atarde.com.br /carnaval/noticia.jsf?id=834588 $>$ Acessado em: 15/04/2009

DAIHA, Nagib. Rituais da Noite. Colunas: Entretenimento e Baladas. 19 Novembro 2009. Disponível em: http://www.axezeiro.com/colunista /22/133,rituais-da-noite.html . Acessado em: 20 de junho de 2010.

DIAS, Clímaco César Siqueira. Carnaval de Salvador: mercantilização e produção de espaços de segregação, exclusão e conflito. Dissertação (Mestrado em Geografia) - Instituto de Geociênci- as, Universidade Federal da Bahia, Salvador, 2002.

FOUCAULT, Michael. Vigiar e punir: História da violência nas prisões. Petrópolis, Rio de Janeiro: Vozes, 1987.

FRANCISCO, Luiz. Bob Sinclar e Mc Leozinho quebram rotina da axé music. Portal UOL Salvador. 14/02/2010. Disponível em: <http: //carnaval.uol.com.br/ultimas-noticias/salvador/2010/02 /14/bob-sinclar-e-mc-leozinho-quebram-rotinada-axe-music.jhtm> Acessado em: 20/03/2010

INFOCULTURA. Carnaval 2007: Uma Festa de Meio Bilhão de Reais. v.1, n.1 Setembro de 2007. Salvador: Secretaria de Cultura do Estado, Fundação Pedro Calmon Centro de Memória e Arquivo Público da Bahia, 2007.

INFOCULTURA. Carnaval de Salvador. v.1, n.3. Salvador, Secretaria de Cultura do Estado, Fundação Pedro Calmon Centro de Memória e Arquivo Público da Bahia, 2009.

MIGUEZ, Paulo Cesar. Carnaval Baiano: As tramas da alegria e as teias de negócios. Salvador: UFBA, 1996. Dissertação de mestrado em Administração - UFBA Universidade Federal da Bahia.

PREFEITURA MUNICIPAL DE SALVADOR SECRETARIA MUNICIPAL DE SAÚDE. Plano Municipal de Saúde 2006-2009. Salvador, 2009.

SANTOS, Milton. Por uma outra globalização: do pensamento único à consciência universal. São Paulo: Edusp, 2000.

SERPA, Angelo Szaniecki Perret. 0 Espaço Público na Cidade Contemporânea. 1. ed. v. 1. São Paulo: Editora Contexto, 2007.

SOUZA, Cláudio Manoel Duarte de. A cibermúsica, djing, tribos e cibercultura. In: LEMOS, André; PALACIOS, Marcos (Org.). Janelas do Ciberespaço - Comunicação e Cibercultura. 1 ed. Porto Alegre: Sulina, 2001.

\section{Referência Fonográfica:}

KRAFTWERK, Techno Pop, 4'20" Em: Electric Café. Kling Klang EMI Warner Bros. 1986 


\title{
Spatial segregation and electronic music: the cultural scenario of Salvador da Bahia
}

\begin{abstract}
The main characteristic of the electronic music is its urban style which was introduced in the academic field through the new modernity paradigms. These paradigms influenced the transformation of the landscape elements and trespassed the continental geographical barriers. In addition to that, they were mixed with other cultural elements responsible for the electronic music transformation. The electronic music, by its introduction on the mass consumption market, has lost its alternative character and has been converted it into a cultural product. This can be illustrated through the contextualization of the main agents of Salvador and Camaçari which segregate the space dedicated to the entertainment. Finally, in this research, the music was applied to narrow the area of social segregation constructed in the city of Salvador and Camaçari. This research was possible through the analysis of the electronic music events, the Mobile-Sound System and VIP areas of electronic music during the carnival, as well as, the raves parties.
\end{abstract}

Keywords: Cultural Geography. Urban Geography. Segregation.

\section{Segregación espacial y música electrónica: el escenario cultural de Salvador de Bahía}

\begin{abstract}
Resumen - La música electroacústica se caracteriza por ser un estilo musical esencialmente urbano el cual se implantó en el ámbito académico entre los nuevos paradigmas de la modernidad. Los paradigmas que cambiaron el estilo de vida de las ciudades han transformado los elementos del paisaje geográfico y transgrediron las barreras geográficas mezclándose con otros elementos culturales. Así fue como se originó lo que hoy conocemos como música electrónica. Después de su introducción en el ámbito del consumo de masas, la música electrónica pierde su carácter alternativo y se convierte en un producto cultural, lo cual se puede percibir a través de la contextualización de los principales agentes del Salvador y Camaçari, en el estado Bahía, cunado éste género musical es separado del espacio destinado para el entretenimiento. En este trabajo de investigación, la música ha sido utilizada para definir los espacios de la segregación construidos en Salvador y en Camaçari. La investigacion fues basada en la observación de fiestas de música electrónica en club nocturnos, en la apropiación del espacio público para la celebración de la fiesta del carnaval por tríos eléctricos y camarotes (las fiestas privadas) de música electrónica y finalmente las fiestas raves.
\end{abstract}

Palabras Clave: Geografía Cultural. Geografía Urbana. Segregación. 